\title{
Medication Errors Are Preventable
}

Harmeet Singh Rehan ${ }^{\star}$ and Shashikant Bhargava

Professor and Head, Department of Pharmacology, Lady Hardinge Medical College, New Delhi 110 001, India

*Corresponding author: Harmeet Singh Rehan, Professor and Head, Department of Pharmacology, Coordinator, Adverse Drug Reaction Monitoring Centre, Lady Hardinge Medical College, New Delhi 110 001, India, Tel: 09811694040; E-mail: harmeetrehan@hotmail.com

Received date: June 22, 2015; Accepted date: July 30, 2015; Published date: August 06, 2015

Copyright: $\odot 2015$ Rehan HS. This is an open-access article distributed under the terms of the Creative Commons Attribution License, which permits unrestricted use, distribution, and reproduction in any medium, provided the original author and source are credited.

\begin{abstract}
The National Coordinating Council for Medication Error Reporting and Prevention (NCC MERP) defines a "medication error" as "any preventable event that may cause or lead to inappropriate medication use or patient harm while the medication is in the control of the health care professional, patient, or consumer. At many occasions a medication error can be caught or is rectified before its administration, thereby preventing harm to patient. This is referred as near miss medication error. Medication errors are broadly classified into prescription error, dispensing error and administration errors. And these errors have significant epidemiological as well as financial burden on healthcare infrastructure. Behavioural sensitization of the involved healthcare professionals can play a vital role in prevention of these medication errors. Also, initiatives at the administrative level of healthcare systems, especially with the implementation of technological tools like computerized physician order entry, barcoding etc. are proving to be a positive steps towards controlling this menace.
\end{abstract}

\section{Introduction}

The National Coordinating Council for Medication Error Reporting and Prevention (NCC MERP) defines a "medication error" as "any preventable event that may cause or lead to inappropriate medication use or patient harm while the medication is in the control of the health care professional, patient, or consumer" [1].

At many occasions a medication error can be caught or is rectified before its administration, thereby preventing harm to patient. This is referred as near miss medication error [2].

\section{Types of Medication Error}

The process of medication use is subdivided into five important stages including prescribing, dispensing, transcribing, preparing and administering of which the processes of prescribing and administering of medication are most vulnerable stages for medication error $[3,4]$. Medication errors are broadly categorized into prescription error, dispensing-related error and errors-related to the administration of medication.

\section{Prescription errors}

Medical prescribing errors (MPEs) are one of the most common and well-studied causes of adverse events. MPEs occurs as a result of a prescribing decision or prescription writing process, and leads to an unintentional and significant (1) reduction in the probability of treatment being timely and effective and (2) increase in the risk or harm when compared with generally accepted practice" [5].

MPE can occur when physician writes a prescription without giving due consideration to patient profile or the involved drug's characteristics, ambiguity in writing prescription order (as in spelling, hand writing or non-standard abbreviations/nomenclatures) or failure to follow system's policies and drug specific instructions. So, errors in prescribing can be divided into irrational prescribing, inappropriate prescribing, and ineffective prescribing, under prescribing and overprescribing, and errors in writing the prescription [6]. Several studies have reported the incidence of prescription errors as high as $39 \%$ [7]. In a prospective study conducted in New Zeland, a total of 36,200 prescription chart were reviewed by ward visiting pharmacist and around $1.5 \%$ of prescribing errors were identified, of these $0.4 \%$ were serious medication errors. In another study, the most common form of prescription error was writing the wrong dose [8]. In six Oxford hospitals, the most common errors on prescription charts were writing the patient's name incorrectly and writing the wrong dose, which together accounted approximately $50 \%$ of all errors. In a hospital study in Norway only $7 \%$ prescription charts were correctly filled, where $79 \%$ had errors that posed minor potential health risks and $14 \%$ had errors that could have led to serious harm [9].

\section{Dispensing errors}

Generally, process of dispensing of medication also includes transcribing and verifying the medication in which mostly nurses and pharmacists are usually involved. There are few studies which have examined and reported the dispensing errors. However, because of their low incidence they are of lesser concern. In an inpatients study Roberts et al reported $11 \%$ of dispensing errors. As per study results, most common errors were due to wrong medicine supply, wrong strength, wrong directions for use, wrong quantity of medicine, and wrong calculation of drug usage. The most common causative factor for such errors was look alike and sound alike medicines [10].

\section{Administration errors}

It is the second most common (38\%) medication error. Bates et al in 1995 reported 26\% of preventable ADEs which occurred during the administration of medication [3]. This stage of medication use is crucial as associated with high risk. Responsibility of such errors lies with nursing staff for indoor patients and with physicians, dentists, pharmacists and patients themselves in outdoor patients [11,12]. The causative factor for administration error is similar to that of prescription and dispensing errors. In addition, it may also include 
Page 2 of 3

omission, wrong dose, wrong route, and wrong patient at wrong time. It may also occur due to technical reasons, e.g. while administering drug using viz nebulizers, infusion pump and MDIs. Patients' noncompliance is another reason for administration errors.

\section{Pharmacoepidemiology of Medication Errors}

Exact incidence of medication errors is difficult to access because only small number of errors is detected and even smaller number of errors is reported. In addition inconsistencies in error reporting, error reporting restricted to inpatient settings, most studies reported errors of commission not the errors of omission are other reasons lack of exact incidence. However, they may occur as frequently as 1 in every 20 prescriptions, and 5 in every 100 medication administrations of these 1 in every 100 medication errors results in patient injury [13].

\section{Pharmacoeconomics}

Medication errors are undoubtedly harmful and puts financial burden to patients, their families, hospitals, healthcare providers and insurance companies. They affect about 44,000 to 98,000 lives/year in US alone, which is far more than the lives affected due to AIDS. The Institute of Medicine report also estimated that more than 70,000 lives are lost per year as a result of medication errors. In USA nationwide hospitals financial burden due to medication error has been found to be between 17-29 \$ billion per years [14].

\section{Detection of Medication Errors}

Medication errors are mainly detected by voluntary reporting by patients, direct observation of actual patient care of inpatients, pharmacy procedures like attending medical rounds or comparison of medication administration record to physician orders, by returned doses to pharmacy, urine testing or tracer drug analysis and

\begin{tabular}{|c|c|}
\hline Category & Example \\
\hline A (No actual error occurred) & Ideal situation \\
\hline B (Actual error occurred but did not reach the patient) & Prescribing error rectified either by nurse or pharmacist \\
\hline C (Actual error reached to the patient) & Prescribed or dispensed wrong medicine (look-alike or sound-alike medications) \\
\hline D (The outcome of the error required monitoring) & $\begin{array}{l}\text { Self-limiting pharmacological actions of medicines e.g. tachycardia following higher } \\
\text { dose of atropine for pre-anesthetic medication }\end{array}$ \\
\hline$E$ (The outcome of the error required intervention) & Toxic dose of digoxin causing arrhythmia required to be managed by phenytoin \\
\hline $\mathrm{F}$ (The outcome of the error required prolong hospitalization) & Paracetamol overdose resulting in hepatotoxicity \\
\hline G (The error resulted in permanent harm) & Intra-arterial administration of thiopentone resulting in gangrene of the limb \\
\hline $\mathrm{H}$ (The error required intervention to sustain life) & Administration of penicillin to already hypersensitive patient to penicillin \\
\hline I (The error resulted in patient death) & Intra-arterial administration of adrenaline in patient of CAD \\
\hline
\end{tabular}

Table 1: NCC MERP categories for medication errors

\section{Prevention of Medication Errors}

Eliminating the aforementioned causes for prescribing, dispensing and administration errors is the first most step towards controlling medication errors. In addition, the NCC MERP has put forwarded certain recommendations to check these medication errors like those related to human errors (as in writing prescription orders or other at comparison of drugs removed from automated dispensing device with that of physician orders, although the system of voluntarily reporting of medical errors is often incomplete and underreported.

Detection and reporting of medication error is the most important component to design the strategies to prevent such errors. Fear of disciplinary procedures for reporting errors has been identified as one of the barrier in detecting and reporting medication error. The establishment of a blame-free, non-punitive environment can overcome such barrier. Health care professionals and patients should be encouraged to report the medication errors, including near-misses. The objective of analysis of medication error is to investigate and detect the underlying factors/root-cause of non-reporting and/or underreporting of medication errors. They should also be encouraged and involved in data collection, cause charting, root cause identification and recommendation generation and implementation. The process development may improve the steps involved in the treatment process [15].

A medication error reporting system should be readily accessible, with clear information on how to report a medication error, and reporting should be followed by feedback. Combination of these methods may improve the reporting of medication errors [16].

\section{Measuring Extent of Medication Errors}

The medication errors are categorized based upon the algorithm developed by NCC MERP into nine categories from A to I (Table 1). Category A indicates circumstances or events that have capacity to cause medical error and with increasing category, propensity of the medical error to translate into direct patient harm increases. Categories A to D indicate no harm to the patient, whereas categories E to I indicate definite harm to the patient with category I indicating possible death because of the medication error [1]. 
communication, standardization of doses and frequencies, preparation and drug distribution system can result in obviate errors in medication use [17].

\section{Role of information technology}

Emerging technologies like computerized physician order entry (CPOE) or smart cards, CPOE with clinical decision support systems, automated drug utilization review system, automated drug dispensing system, bar coding, clinical pharmacy information system can provide patient care with high accuracy, efficiency and promising advancement [18-22]. However, in spite of many studies advocating use of these tools to lessen medication errors, their implementation in routine healthcare practice is still inadequate [23].

\section{Conclusion}

Medication errors are becoming a major threat to patients' safety. They lead to increased morbidity and mortality rates, cost of treatment and at times hospitalization. Therefore identifying the causes of medication errors and developing need based strategies viz. educational and managerial level interventions and incorporating new information technologies in the existing healthcare system may prove to be viable, cost-effective and sustained option to prevent medication errors.

\section{References}

1. National Coordinating Council for Medication Error Reporting and Prevention (NCC MERP).

2. Acute care ISMP medication safety alert.

3. Bates DW, Boyle DL, Vander Vliet MB, Schneider J, Leape L (1995) Relationship between medication errors and adverse drug events. J Gen Intern Med 10: 199-205.

4. Bates DW (1996) Medication errors: how common are they and what can be done to prevent them. Drug Safety 15: 303-310.

5. Dean B, Barbera M, and Schachter M (2000) What is prescribing error? Qual Health Care 9: 232-237.

6. Aronson JK (2009) Medication errors: what they are, how they happen, and how to avoid them. QJM 8: 513-521.

7. Flynn EA and Barker KN (1999) Medication error research. In: Cohen MR, ed., Medication errors: causes and prevention. Washington, DC American Pharmaceutical Association.
8. Dean B, Schachter M, Vincent C, M Barber (2002) Prescribing errors in hospital inpatients: their incidence and clinical significance. Qual Saf Health Care 11: 340-344.

9. Ritland S, Kummen M, Gjerde I (2004) Feil og mangelfull kurveføringen potensiell kilde til feilmedisinering. Tidsskr Nor Laegeforen 124: 2259-2260.

10. Roberts DE, Spencer MG, Burfield R, Bowden S (2002) An analysis of dispensing errors in UK hospitals. Int J Pharm Pract 10: R6.

11. Cebeci F, Karazeybek E, Sucu G, Kahveci R (2015) Nursing students' medication errors and their opinions on the reasons of errors: A cross-sectional survey. J Pak Med Assoc 65: 457-462.

12. Cloete L (2015) Reducing medication errors in nursing practice. Nurs Stand 20: 50-59.

13. Thomas EJ, Petersen LA (2003) Measuring errors and adverse events in healthcare. J Gen Intern Med 18: 61-67.

14. Van den Bemt PM, Postma MJ, Van Roon EN, Chow MC, Fijn R, et al. (2002) Cost-benefit analysis of the detection of prescribing error by hospital pharmacy staff. Drug Saf 25: 135-143.

15. Wichman K, Greenall J (2006) Using root cause analysis to determine the system based causes of error. CPJ/RPC 139: 63-65.

16. Barker KN, McConnell WE (1962) The problems of detecting medication errors in hospitals. Am J Hosp Pharm 19: 360-369.

17. Skiba $M$ (2006) Strategies for identifying and minimizing medication errors in health care settings. The Health Care Manager 25: 70-77.

18. Oren E, Shaffer ER, Guglielmo BJ (2003) Impact of emerging technologies on medication errors and adverse drug events. Am J Healthsyst Pharm 60: 1447-1458.

19. Stokowski LA (2001) Using technology to improve medication safety in the newborn intensive care unit. Adv. Neonatal Care 25: 70-83.

20. Stolarz SA, Hartnell N, MacKinnon NJ (2005) Approaches to improving the medication use system. Healthcare Quarterly 8: 59-64.

21. Fischer JR (2014) The impact of health care technology on medication safety. S D Med 67: 279-280.

22. Jozefczyk KG, Kennedy WK, Lin MJ, Glass MD, Eidam WS, et al (2013) Computerized prescriber order entry and opportunities for medication errors: comparison to tradition paper-based order entry. J Pharm Pract 26: 434-437.

23. Radley DC, Wasserman MR, Olsho LE, Shoemaker SJ, Spranca MD, et al. (2013) Reduction in medication errors in hospitals due to adoption of computerized provider order entry systems. J Am Med Inform Assoc 1: $470-476$.
This article was originally published in a special issue, entitled: "Medication Errors", Edited by Dr. Prashansa Agrwal, University of Arizona, USA 